\title{
DISCUSSION OF POT BEARING FOR CONCRETE BRIDGE
}

\author{
Yan-Chyuan Shiau \\ Associate Professor \\ Dept. of Const. Engr., Chung Hua University \\ 707, Sec.2, WuFu Rd., HsinChu, Taiwan \\ ycshiau@ms22.hinet.net \\ Ming-Teh Wang \\ President of Taiwan Const. Research Institute \\ 11Fl., No.190, Sec.2, Chung-Hsing Road, Hsin- \\ tien, Taipei, Taiwan \\ mtwang@tcri.org.tw
}

\author{
Chih-Ming Huang \\ Graduate Student \\ Institute of Const. Magr, Chung Hua University \\ 707, Sec.2, WuFu Rd., HsinChu, Taiwan \\ jimmy_huang@ispeed.com.tw \\ Jin-Yi Zeng \\ Graduate Student \\ Institute of Const. Magr, Chung Hua University \\ 707, Sec.2, WuFu Rd., HsinChu, Taiwan \\ iamjohnjohn2002@hotmail.com
}

\begin{abstract}
Road engineering consists of three major structures, road embankments, bridges, and tunnels. In consideration of the cost of land acquisition in urban areas, the trend of road engineering migrating to hilly or mountain areas has been developed. Under such topographic restrictions, enormous bridge constructions would certainly be the consequence. After the National Freeway No.3 brought in innovative bridge construction methods, bridge bearings have almost entirely taken place by pot bearing. Pot bearing has many advantages: the extremely long service year (anything else?). In addition to the correct installation, the routine inspections and maintenance of pot bearings in the service time are necessary for them to fully function. Current domestic research mainly concentrates on rubber bearings and has only few discussions and analyses on pot bearings. By collecting the real cases, this article discussing and analyzing the types of damage and their causes in the phases of designing and manufacturing through installation and maintenance provides relevant people a reference of the approaches for prevention and improvement.
\end{abstract}

\section{KEYWORDS}

Pot bearing, Elastomer, Reinforced Concrete Bridge, Damage Prevention

\section{INTRODUCTION}

A bridge structure can be divided into two main bodies, the superstructures and the substructures; the superstructure bears its own weight and the traffic load, and the substructure bears the load from the super- structure. The transmission media is the "bearing", one of the most important components of a bridge structure. Pot bearing was first used on Germany's bridge in 1958; after years of development, it has gradually become the most widely used metal bearing in the world's bridges. Pot bearing places an 
Elastomer inside a steel pot and presses the top of the Elastomer by using a steel plate; the Elastomer functions like a viscous fluid inside a hydraulic jack and the top steel plate behaves like the piston. Inside the pot the Elastomer is to be laterally restricted, is not able to be compressed, and not able to horizontally lengthen. The bearing can hold substantially high pressure and enable slight rotations under homogeneous compression stress; these aforementioned items are the principle of a pot bearing [1]. It has following advantages:

1. Ability to carry extremely high loads;

2. Various types to meet the needs of design;

3. Low friction coefficient and large movement;

4. Ability to be designed for vertical tension;

5. Higher allowable compression stress, which reduces bearing size; and

6. High durability.

\section{COMPOSITION OF POT BEARING AND ITS TYPES}

A Pot bearing mainly consists of the components made of steel plat, rubber, Teflon, brass, and stainless steel. The main components include anchor bolts, upper and lower masonry plates, upper plat, pot, piston, elastomer, brass ring, sliding device, movement gauge, dust skirt, and connecting bolts, as shown in Figure 1;

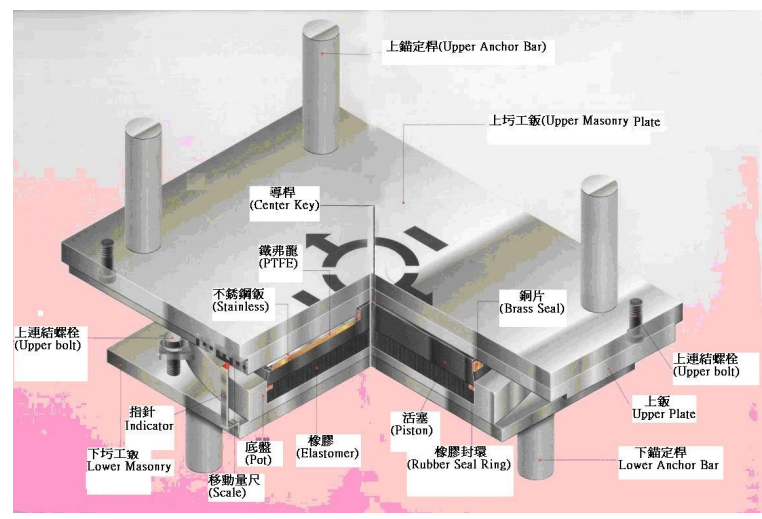

Figure 1. Components of Pot Bearing

Pot bearing has tree types, the fixed bearing, the guided bearing, and the free bearing [2]:

\section{Fixed Bearing}

Fixed bearing does not allow bearing plane twodirection movements, but allows it to rotate. Components of the bearing include base pot, piston, and enclosed rubber rotation element. To provide a good rotating ability, the top and bottom of the rubber rotation element are each coated with a PTFE layer or greased with non-aggressive lubricant.

\section{Guided bearing}

Guided bearing allows rotation and the bearing plane to do one-direction movement. The main components of a guided bearing are the same as those of a fixed bearing, but are able to provide longitudinal movement function. It needs a sliding plate on the top of the piston. Its piston top needs to be attached with a PTFE coated sheet, with which the smoothly polished stainless plate adhered to the bottom of the upper sliding plate forms a nice sliding contact surface. Guide bar or guide plate is used to limit the bearing to provide only longitudinal movement function.

\section{Free bearing}

Free bearing allows rotation, longitudinal movement, and transverse movements. The main components of a free bearing are the same as those of a fixed bearing, but are able to provide two-direction movements. Its piston top is attached with a PTFE coated sheet and supports a steel upper sliding plate, which needs a polished smooth stainless plate adhered to the contact surface between PTFE and the sliding plate to promote sliding movement.

\section{DISCUSSION OF DESIGNING AND MANUFACTURING POT BEARINGS}

\subsection{Current standards for designing and manu- facturing of pot bearing}

1. The owners' specifications for meeting their own requirements;

2. The standards by the American Association of State Highway and Transportation Officials (AASHTO), Standard Specification for highway bridges", 16th edition; and

3. The standards by the European Committee for Standardization (CEN), prNE1337. 
The main material used for pot bearing is steel plate, which generally has approximately 60 designed service years according to the steel structure standards. The most common problems in design and manufacturing are as follows:

\subsection{Poor Design Spaces of Components}

Pot bearing mainly is an assembly of steel components, and it needs to integrate with both super- and substructure; furthermore, it would have to face issues on maintenance or replacement of parts during its service time; the reserved space for each component interplays with one another. A good design must consider the spaces for installation of bearing during bridge construction and for maintenance in the future. The following figure shows a case for an inappropriate designed space for bearing (Figure 2).

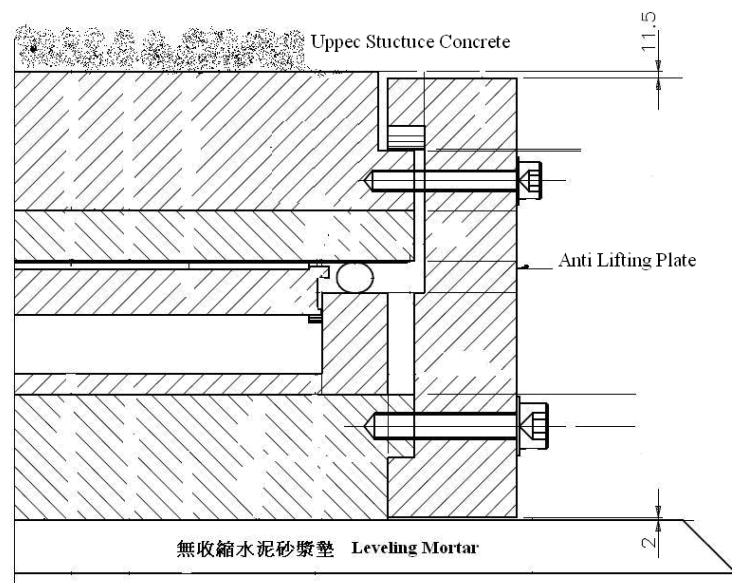

Figure 2. Inappropriate Designed Spaces for Pot Bearing

The gap between the anti-lifting plate and the superstructure have a distance of only $11.5 \mathrm{~mm}$, where also the indicate attaches, making the construction of superstructure difficult. The construction workers make the base formworks by directly using antilifting plate underpinned with Styrofoam or boards, which creates dead corners during form removal and blocks the movement function of the indicator (Figure 3). In addition, the anti-lifting plate is designed to enable side removal for the replacement of base pot after unscrewing the bolts connecting the lower masonry plate. It is very unreasonable to design that the distance between the base and the non-shrink grout is only $2 \mathrm{~mm}$, which is quite difficult in the aspect of construction control of masonry works. By all means, a design should avoid this kind of narrow interval, which would be difficult for construction or may be clogged with extraneous objects.

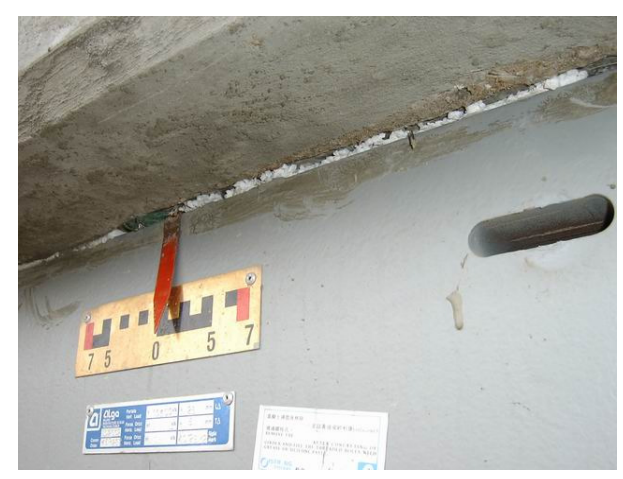

Figure 3. Indicator Cannot Move

\subsection{Using Materials that is Not Durable}

Current pot bearing standards has stringent criteria for materials used in steel plates; however, they do not set up specific requirements for the materials used for accessories, like indicator and scale of movement measurement or dust skirt. Other than the required long durability, the surface of the indicator and scale are required to use prominent, bright colors for observation of the bridge from a distance. In this case, after 20 months of bearing installation the scale already faded too much to be legible for its readings of movement (Figure 4). The indicator was so eroded to remain in use and the skirt is too broken to keep its function (Figure 5). The qualify of materials used in pot bearing is apparently not commensurate with that of a product like pot bearing having such long service years; therefore, the maintenance cost incurs.

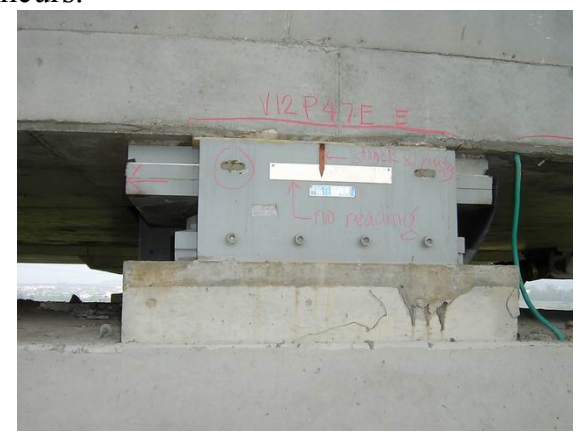

Figure 4. Illegible Readings Due to Faded Scale 


\subsection{Selection of Corrosion Prevention Methods}

Other than using a few amount of rubber, PTFE, and brass, pot bearing use a steel plate for its main body; to enable the bearing to reach its service years, corrosion prevention of its surface is the most important topic. Surface preparation before painting on steel hugely affects the life of a paint film; one research study shows that the factors accounting for the life of a paint film include the following: $49.5 \%$ for surface treatment, $19.1 \%$ for paint film thickness, $4.9 \%$ for paint type, and $26.5 \%$ for all other factors (e.g. construction environment, steel surface conditions, etc.). Therefore, the surface treatment is important for a painting work [3].

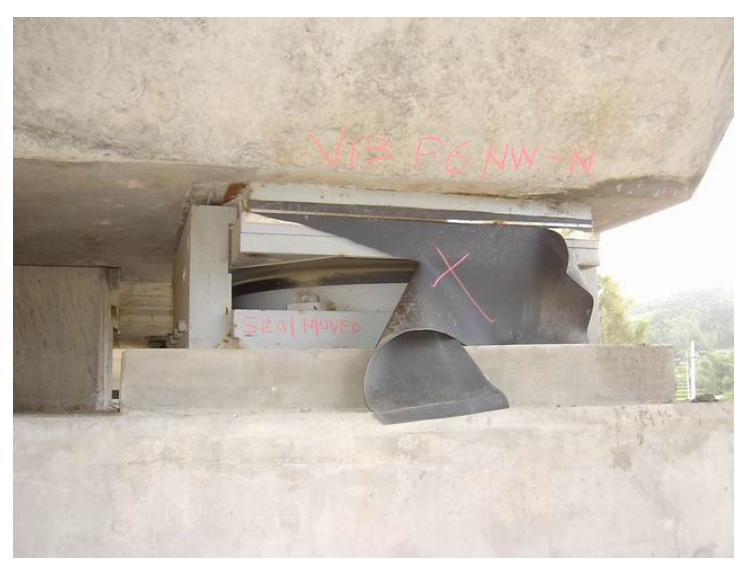

Figure 5. Broken Dust Skirt

The steel surface of a bearing applied with painting method generally uses sandblasting. An industry commonly adopted surface treatment for metals, Sandblasting uses air to blow light-density sandblasting media or fan-powered air to blast heavier sandblasting media against the surface of a metal to remove rust, welding slag, stains, and oxidants on the surface of a metal as well as residual stress on its surface. In addition, the sandblasted surface creates textures, which promote their binding with anticorrosion paint. Sandblasting materials generally can be aluminum oxide, iron sand, aluminum bead, iron bead, or glass bead. The sandblasting surface treatment of bearing at least has to meet "near white" metal standard of Swedish SIS SA 2 1/2. The suggested roughness by sandblasting is from 25 to $50 \mu \mathrm{m}$. Not diligently performed sandblasting work will result in a poor binding between the paint film and the surface, peeling-off due to poor bonds, and then rusting of steel plate. The common negligence that happens in sandblasting works includes the following:

1. Use of recycled sandblasting media;

2. Incompliance with standards of SIS SA $21 / 2$;

3. Working environment during sandblasting or painting, for example humidity and dust;

4. Painting not performed within 4 hours after sandblasting; and

5. Inappropriate contacts with sandblasted surface, for example, workers' touches.

Surface treatment of a metal may use Ultra-High Pressure Water Jetting employing pressure higher than 25,000 psi as a better alternative rather than use sandblasting. Figure 6 shows a comparison between the sandblasting and the pressure water jetting treated surfaces. Besides the pressure water jetting is better than the sandblasting in the surface treatment of a metal, it has the following advantages [4]:

1. No air pollution issues;

2. Reduction of wastes;

3. Improvement on operators' working environments;

4. No harms to the surrounding transmission machines;

5. Better quality of surface than that by sandblasting;

6. No sparks.

Among the anti-corrosion methods used after sandblasting, the painting method is still widely applied on top bearing because of its low cost; however, more and more manufacturers employ Zinc Metal Spray, which applies short circuit to zinc wires, generates high heat to melt them, and then use high pressure air to spry them on surface treated steel plates (Figure 7). If the steel plate for such spray is not sandblasted or not appropriately treated, the melted metal wires can not adhere to its surface; therefore, the employment of zinc metal spray is equivalent to a direct assurance for the quality of surface treatment [5].

Today the longest life the paint film of corrosionresistance paint could have is theoretically up to 15 
to 18 years. But if the construction quality control is poor, in practice, corrosion would begin in about 2 to 3 years and repainting would be needed in 6 to 8 years. In order to achieve long term corrosion protection and to lower the cost of the period of life, it is necessary to consider alternative corrosion protection methods in place of the paint-based methods [6]. Zinc metal spray has a long-term economic benefit superior to that of painting method. Especially with the endlessly rising wedges and the awareness of environmental protection and traffic, the cost and difficulty of in-situ maintenance will raise, which much more manifest the zinc metal spray method superiority. Although the zinc metal spray costs 1.6 to 1.8 times higher than the painting method does, its anti-corrosion ability is excellent and in the aspect of long-term maintenance its cost is more competitive than that of a painting method.
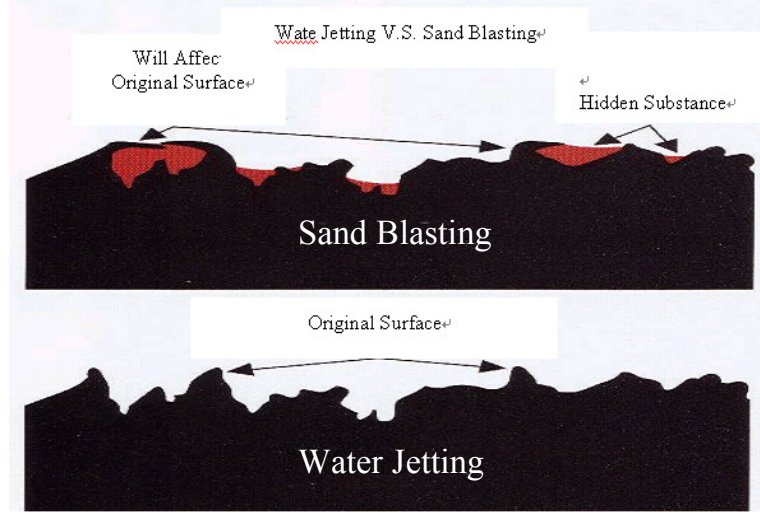

Less remain substane, do not need secondary

Figure 6. Comparison between Sandblasting and UltraHigh Pressure Water Jetting

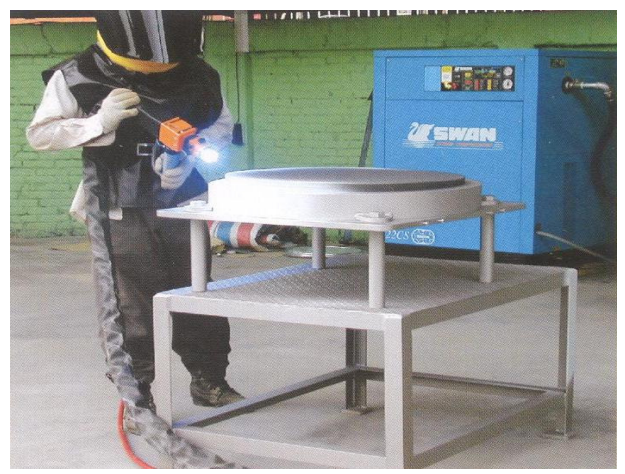

Figure 7. Zinc Metal Sprays on Pot Bearing

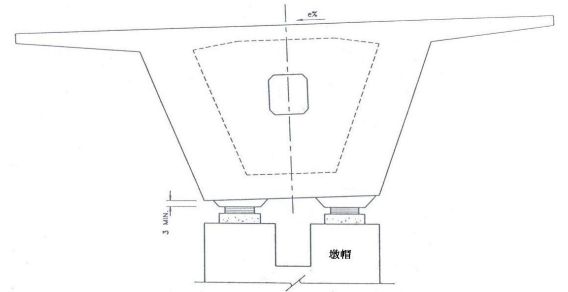

Figure 8. Wedge Shape Levelling Pad

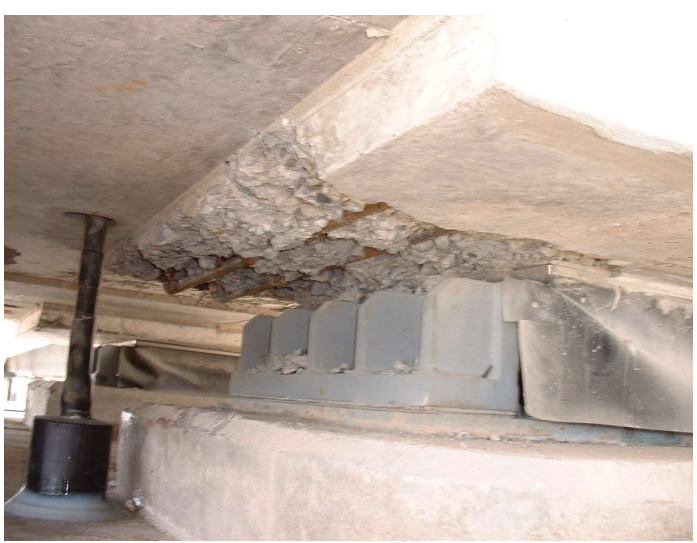

Figure 9. "Rectangular Shape" Levelling Pad

\subsection{Inappropriately Designed Levelling Pad}

The design of the connection between a superstrucure and a bearing can affect the concrete pouring too. Bearing installation must be horizontal to correctly transmit the structure loads without creating eccentricity and component forces. However, the superstructure needs longitude grades and transverse grades (excess heights) in order to agree with the geometries of the road lines, which results in the fact that the superstructure cannot horizontally join with bearings; therefore, in design a levelling pad is installed onto the bottom of a superstructure to connect with bearings. Generally, "wedge shape" levelling pads (Figure 8) are used to enable better concrete mobility at the bearings. Figure 9 shows a case of an inappropriately designed level pad that uses a "rectangular shape" levelling pad, which diminish the concrete mobility and resulting in cellular structures and voids. 


\section{DISCUSSION OF THE INSTALLATION OF POT BEARING}

Before installation, all bearings need visual inspections to prevent the damages from transportation and storage. The installation of pot bearings of a concrete bridge has following four steps:

\section{A. Recessing Spaces for Anchor Bolts}

Before pouring concrete for the substructure and the concrete plinth, spaces for the bottom anchor bolts of pot bearing are recessed. Normally, the galvanized pipes for pre-stress are cast for the recess spaces (Figure 10). The concrete for the pot bearing base needs surface roughening in order to help the ties of the subsequent grouting.

Anchor Hole

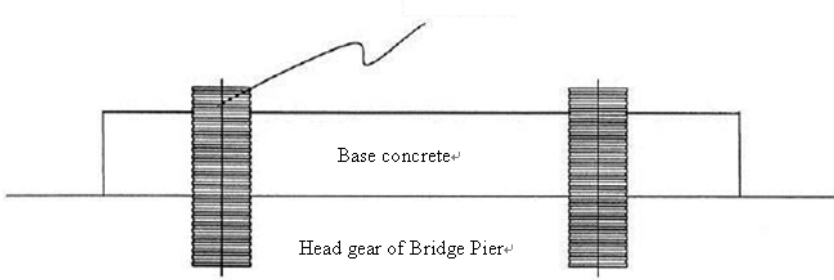

Figure 10. Illustrations for the Installation of TCM Pot Bearing (Step 1)

B. Placing and Levelling Bearing

After pouring anchor and bearing base, place the pot bearing base into the recessed spaces, position it with theodolite and spirit level, and reserve the spaces for non-shrinkage cement mortar bed, as shown in Figure 11.

\section{Non-Shrink Cement Mortar Grouting}

After positioning the bearing base, non-shrinkage cement mortar is poured in the surrounding area. The thickness of the non-shrinkage mortar bed is from $20 \mathrm{~mm}$ to $50 \mathrm{~mm}$ (Figure 12).

D. Superstructure (Girder) Concrete Pouring

After the installation of bearing on bolts, the construction of superstructure can be preceded; upper anchor bolts of pot bearing are placed and concreted in the end diaphragm beam of superstructure (Figure $13)$.

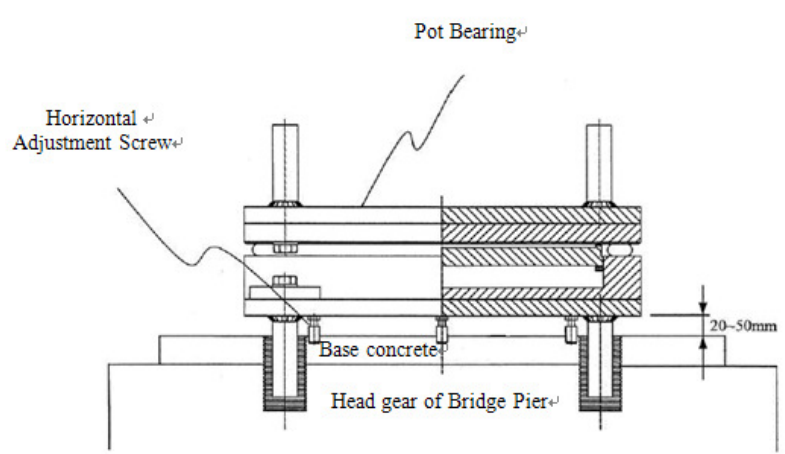

Figure 11. Illustrations for the Installation of TCM Pot Bearing (Step 2)

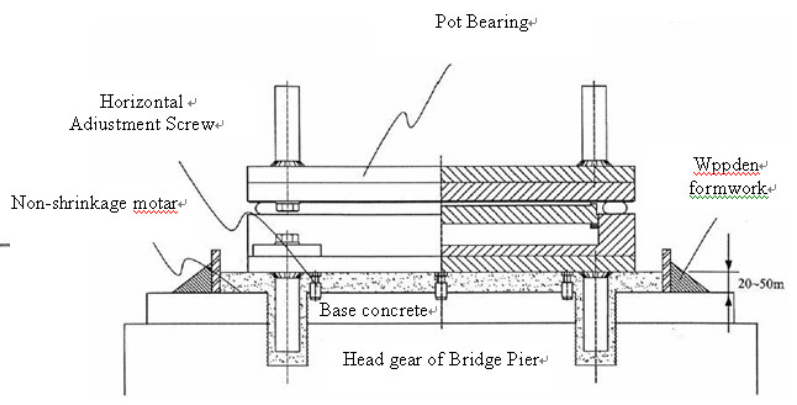

Figure 12. Illustrations for the Installation of TCM Pot Bearing (Step 3)

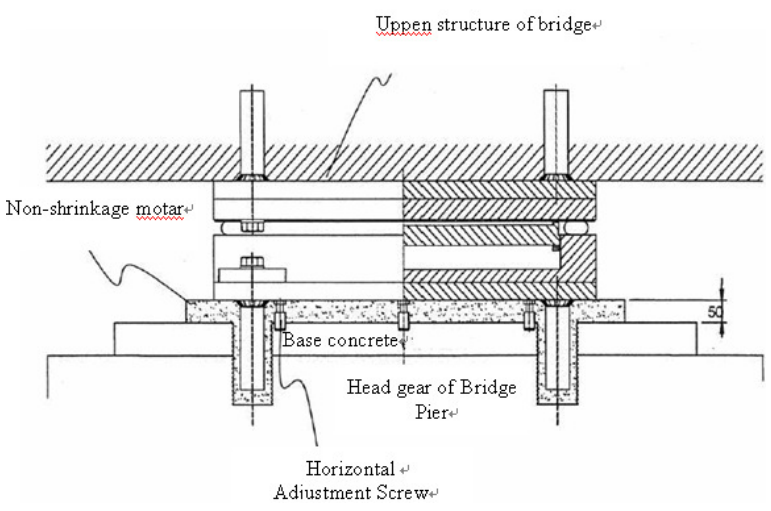

Figure 13. Illustrations for the Installation of TCM Pot Bearing (Step 4)

The most happened faults during the installation of pot bearings are listed as follows: 


\section{E. Wrong Placement}

In this case a pot bearing is designed as guided sliding type but misplaced as fixed type. Not only are the allowable load and rotation not compatible, but also the allowable movement is shorter for fixed type, resulting in the bearing upper plate sliding out of base pot, decreasing the effective load area, and lowering the load capacity (Figure 14). According to Standard EN1337-1, before each bearing is shipped, it shall have a unique name plate, made of aluminum or stainless and attached on its body [7], for identification of the bearing's information, such as position number, vertical and horizontal allowable loads, longitudinal and transverse allowable movements, rotation; the name plate is deemed a permanent device of the bearing. It functions as the identification of the bearing so that worker can immediately recognize and retrieve correct original design information. Under the situation that each bearing can be identified clearly, wrong placement of a bearing shall not happen.

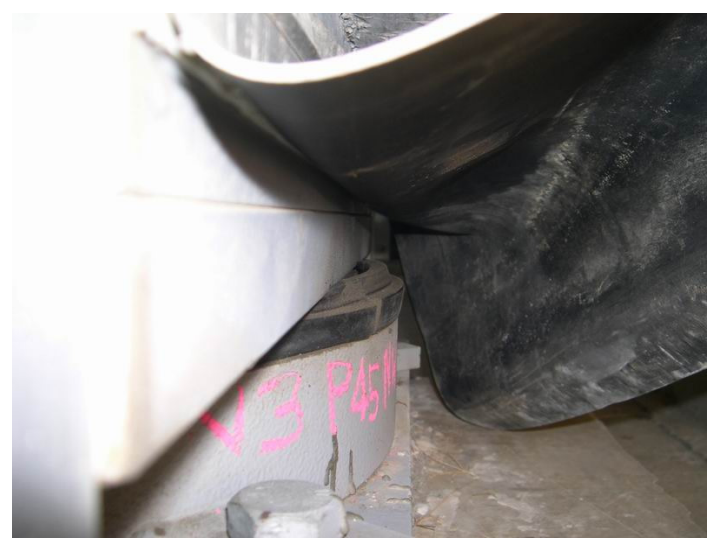

Figure 14. Upper Plate Slides out of Base Pot

F. Wrong Timing to Remove the Temporary Fastening Devices

For considering the consequences of installation and transportation, pot bearing will be clamped with bolts after the leveling adjustment and the alignment of the centers of upper and lower plates before shipping. After bearing installation, bridge structure starts to have movement by factors, such as changes in temperature and creeps; especially the shortening of bridge is severer at when the camber happens af- ter the bridge is prestressed. Therefore, the bolts temporarily fastened to the upper sliding plate during manufacturing and transportation need to be removed after the bearing is stalled, but before the superstructure is pre-stressed (if prestressed concrete bridge). During the bearing in service, it is common to find the fault of installing bearing that the temporary fastening devices were not removed; after service starts, many bridges are found during their maintenance inspections that the installation connection plate (fastening device) was not removed, which causes the superstructure to deform and itself to bend or rupture [8].

Another situation is that the fastening bolts were removed too early but not installed back. The purpose of removal of the bolts is for presetting, a preset adjustment for compensating the longitudinal changes caused by the superstructure's shrinkage, creep and surrounding temperature. The early removal of the temporary bolts itself is not a problem, but it would be when the temporary bolts are not installed back, causing free movement of the upper plate to be too large and resulting in insufficient allowed movements in the future (Figure 15), and even causing the upper plate to tilt greater than the allowed rotation

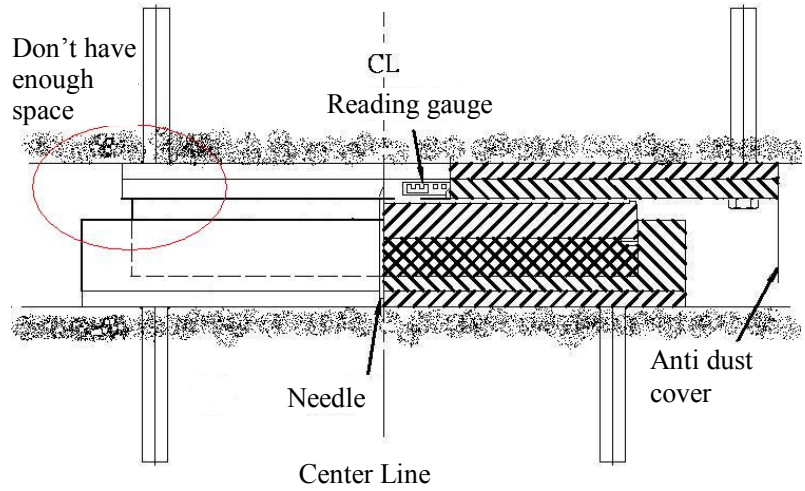

Figure 15. Upper Plate Moves too Huge

\section{G. Inappropriate Concrete Pouring}

Inappropriate concrete pouring causes cellular and voids in the concrete surrounding the upper masonry and lower masonry. The load of pot bearing is calculated as $45^{\circ}$ load dispersion angles downward from the elastomer and upward from piston disc (or 
PTFE) [9]. If concrete in this load dispersion zone has too huge cellular or voids, the concrete compression strength will be lowered and will possibly cause superstructure collapse. The cellular or voids cause the concrete to be damaged, on which its contact with bearing masonry becomes unevenly, topically stressed. The uneven contact stress, for example, direct contact between reinforced rebars and bearing, and uneven concrete contact surface, forms the phenomena of uneven stress transmission and stress concentration, which cause bearing plates to be deformed (Figure 16) or bearing to be inclined.

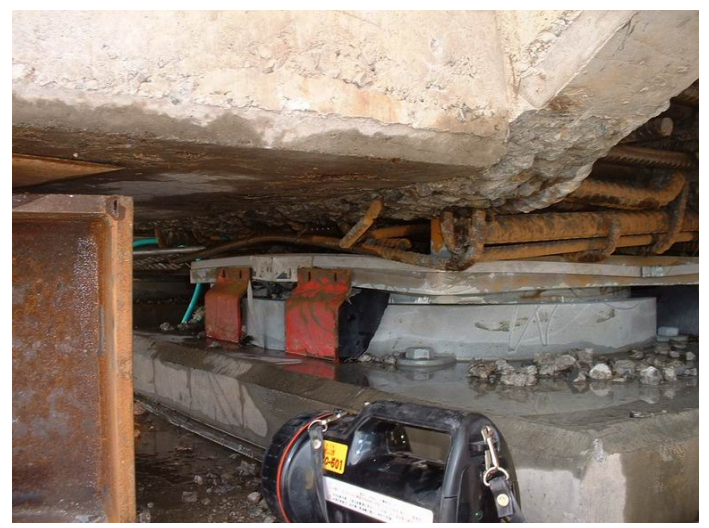

Figure 16. Plate of Pot bearing Deforms

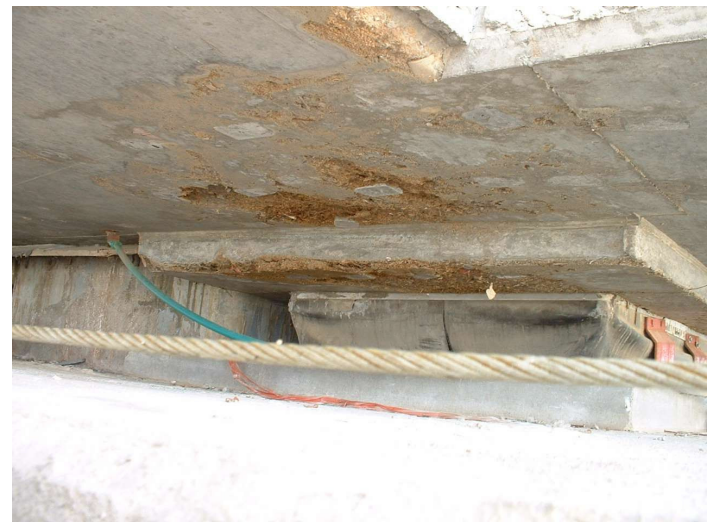

Figure 17. Concrete surrounding bearing attached with extraneous objects

Bearings all are located on the bottommost of the superstructure, the concrete pouring has been not easy; in addition, if the concrete has poor mobility or the construction workers are negligent, the chance of cellular or voids would be rather high. Furthermore, because of the gravity, wood chips, wires, and all other debris generated during construction will be collected here. If the care of cleaning work is not specifically taken, in less serous situation wood chips attaching to concrete surface would affect the aesthetic (Figure 17); more seriously, huge garbage, such as bottle and plastics, buried near the concrete of bearing will lower the effective load capacity, which affect bridge's structure safety.

Problems of cellular, voids, and extraneous objects can be prevented by the following methods:

1. Utilize supplementary vibrating systems, such as external formwork vibrator;

2. Use high mobility concrete, such as High Performance Concrete or Self-Compacting Concrete. Or, by concrete mix ratio, use chemical admixtures or blast furnace slag to improve concrete mobility or workability.

3. Set temporary windows for internal vibrator at levels in different height. Seal the window of the level at which the vibration requirement is met; then, move concrete pouring to a higher level.

4. Open cleaning holes on the bottom of the girder, in order to allow extraneous objects to be cleaned out.

In addition, the spacing of rebar near the bearing is too small because of the dense arrangement of shear rebar and reinforced bars in prestress anchor or for load zone. Other than the designed arrangement bars, there are many additional working bars. And a portion of bar splicing occurs within this area. The quantity of tie wires increases as the quantity of bars increases. These usages of spaces decrease the concrete mobility, causing cellular and voids. To avoid such dense arrangement of reinforced bars, the following solutions can be adopted:

1. Appropriate reinforcements;

2. Use of stirrups;

3. Avoid bar splicing nearby the bearings or the use of coupler; and

4. Avoid or decrease the quantity of working rebar nearby bearings. 


\section{MANAGEMENT OF POT BEARING AND OTHER ISSUES}

\section{A. Lax Inspection}

Self-inspection of each phase become pro forma and is not performed diligently, causing damages that should not happen, such as wrong placement, and temporary fastening device not being removed.

B. Insufficient Training and Knowledge

Bearing installation and repair are highly professional tasks that shall be supervised by professionally trained engineers. However, commonly, professional training on installation inspections and repairs are not given; instead, possibly only one or two times of installation demonstration delivered by the manufacturers are done on site. The case here finds the fact that engineer who does not comprehend the bearing's function and principle repaints the stainless plate of the sliding elements when in bearing's paint repair, affecting the sliding functions (Figure 18).

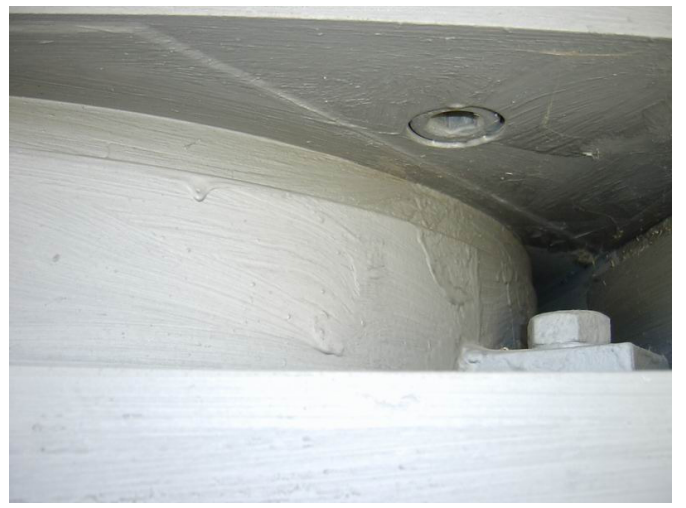

Figure 18. Damage on Stainless Plate of Pot Bearing

C. Collisions during Transportation, Storage, and Installation

Even the lightest pot bearing have a main body that still weighs at least several hundred kilograms; therefore, using a crane and hoist to store bearing or place it in position is a normal task. The collisions during a lifting process will easily cause the anticorrosion paint to fall off. Also workers do not follow the normal procedure to inspect and repair, which cause steel portions of bearing corrosion later.
The following measures can be adopted to avoid this kind of fault:

1. Wrapping can protect coatings of bearing in lifting; and

2. When collision causes damage, correct method shall be used to repair surface paints.

\section{INSPECTION AND MAINTENANCE FOR POT BEARING}

According to prEN 1337-10, pot bearings have two inspections, regular inspection and principle inspection [10]

\subsection{Regular Inspection}

The following items need to be performed in a regular inspection:

1. Whether the spare movements are still enough, of which the temperature effect needs to be consider.

2. Visible defects

(1) Cracks;

(2) Incorrect position; and

(3) Unanticipated movements and deformations.

3. The condition of base and anchor;

4. The conditions of corrosion protection, dust protection, and seal;

5. The conditions of sliding and rotation surfaces

6. Visible defects near structural components.

\subsection{Principle Inspection}

The frequency of principle inspection shall be less than that of a regular inspection. Also, a few components will be replaced after the principle inspection. This inspection will document the conditions of the devices, which are thoroughly analyzed. This analysis ensures that the device will continue its anticipated operation as long as the coming of the next principle inspection. Principle inspection includes every item of regular inspection and also the following items:

1. Bearing's Sliding Components that Contain PTFE 
Feeler gauge shall be used to measure the height (h) between the sliding surface and the plate fitted with PTFE (Figure 19). According to the experience of Germany's Department of Transportation, the abrasion of PRFE shall focus on checking its visual height [11]:

If $\mathrm{h} \geqq 1.0 \mathrm{~mm}$, bearing is normal.

If $0.5 \mathrm{~mm} \leqq \mathrm{~h}<1.0 \mathrm{~mm}$, changes in height shall be measured annually.

If $0.2 \mathrm{~mm} \leqq \mathrm{~h}<0.5 \mathrm{~mm}$, inspection interval shall be shorten, PTFE shall be replaced or authenticated by expert.

If $h<0.2 \mathrm{~mm}$, PTFE shall be replaced or authenticated by expert.

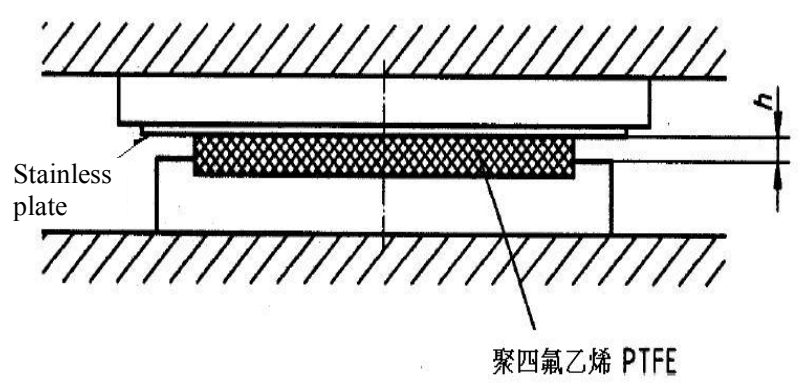

Figure 19. Measuring PTFE of Pot Bearing

\section{Contact Area between Piston and Pot Base}

Measure and document the contact area between piston and pot base, $\mathrm{S} 1 \mathrm{~min}$ and $\mathrm{S} 1 \mathrm{max}$, as shown in Figure 20.

EN1337-10 suggests to perform principle inspection and to document it within the first year of the formal service commencement after the completed installation. In general, manufacturer's warranty is based on the premise that the bearing shall be inspected within one year of completed installation and be under required maintenance to ensure the bearing's functionality and durability.

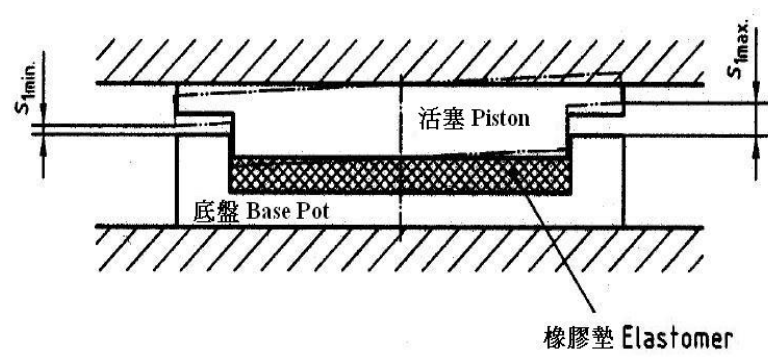

Figure 20. Illustration of Measuring the Bearing Piston and the Base Pot

\section{CONCLUSIONS AND RECOMMENDA- TIONS}

\subsection{Conclusions}

Pot bearing has the potential factors that will cause its damages through the stages from design, manufacturing, installation, to maintenance. However, self-inspection and quality inspection often become pro forma and are not performed diligently. Pot bearings are customized products. Each one of them has its own unique identification label. After layers of quality control in production process and selfinspection during installation, many faults and damages that should not happen are still found in the inspection during the service time; these issues manifest the fact that the engineering staffs does not have enough professional knowledge of pot bearing and common sense. The bridge designer focuses only on the structure requirements and does not understand its design and construction. The bearing manufacturer does not fulfill their responsibilities to its customer on training, technology transfer, and supervisory. The installation contractor lacking of knowledge of pot bearing loosens the administration to crash for service commencement. Relevant parties shall reinforce their operation management at each stage. In addition, the bridge designer, pot bearing manufacturer, and installation contractor need to improve their intercommunication at each stage and enable one another to understand the linkages and interfaces that need to be noticed at each stage, by which the pot bearing can function to its maximum extent. 


\subsection{Recommendations}

Give routine training or a seminar to relevant staff to improve their professional knowledge, especially to the chief engineer.

Self-inspection needs to be implemented thoroughly rather than just perfunctory. Defects the occurred in transportation and lifting need immediate repairs. Perform principle inspection and document it within the fist year of the formal service commencement after the completed installation.

1. Pot bearing has a service time lasting decades, therefore the durability of its material and surface corrosion protection are extremely important. Especially for the owner, the trade-off relationship between the initial procurement cost and the future maintenance fee needs to be considered seriously. Particularly for the higher bridges, the required preparation works for inspection generally cost more than the maintenance cost of the bearing. For example, the cost of scaffolding for pillars of fairly tall bridges or the land leasing cost for hard accessed bridge.

2. Designer of pot bearing shall consider the relative position between the forms and the rebar during installation, and the working spaces for installation and future maintenance. If Anti-lifting devices are installed to free or guided pot bearings, they shall not hinder bearings' movements, installation, and the convenience for replacement.

The degree of delicacy of the concrete surrounding a pot bearing matters for the success of the bearing installation. Therefore, the cement mix ratio of concrete at this point needs special care; it even needs to use high performance concrete that has better workability and mobility, or self-impacting concrete. Before pouring, forms near bearing located at the bottom of the girder need a clean hole to facilitate the clean work. Also windows at various levels shall be opened to enable thorough performing of levelled concrete vibration.

\section{REFERENCES}

[1] Chou, Shui-hsing and Hsiang, (October 2001) Chung-fu. Bridge Engineering (II). China: Chonqqing University Press and Xinjiang University Press,.

[2] Taiwan. Ministry of Transportation and Communications ROC. Design Code and Specification for Road and Bridge Design. Taiwan, R.O.C.: Youth Cultural, (April 2002).

[3] Taiwan. China Corporation Register of Shipping. Technical Circular No. 25, (January 2006).

[4] Huang, Ming-tse. (December 2006) "Ultra-High Pressure Water Jetting." Presentation. First Maintenance Office Directorate General of Highways Ministry of Transportation and Communications ROC,

[5] Taiwan Pillar Industry. Advertisement. (November 2007)

$<$ http://www.taiwanpillar.com.tw/about.php?mode= $4 \& \mathrm{id}=18>$.

[6] Chuang, Chiu-ming. (July 2002) "Durable Zn-Al Low Temperature Metal Spray for Steel Structure." Taiwan Highway Engineering 29-1,

[7] European Committee for Standardization. prEN 1337-1 Structural Bearings- Part 1 General Design Rules. (June 2000).

[8] Chou, Ming-hua(May 2006). "Case Analysis and Prevention of Typical Faults of Pot Bridging of Bridge." 2006 China Civil Engineering Papers. China Railway Society. China: Southwest Jiaotong University Press.

[9] European Committee for Standardization. "prEN 1337-5 Structural Bearings- Part 5 Pot bearings." (March 2005).

[10] European Committee for Standardization. "prEN 1337-10 Structural Bearings- Part 10 Inspection and Maintenance." (July 2001).

[11] Chuang, Chun-sheng. (May 2004) "Bridge Bearing". Beijing, China: China Railway Publishing House. 